\title{
Energy and Its Interplay with Global Corporate Social Responsibility and Sustainability Efforts
}

\author{
Amber A. Smith-Ditizio, amberanaylmt@gmail.com* \\ Terry Damron, DamronT@apsu.edu \\ Amye Melton, MeltonA@apsu.edu
}

\begin{abstract}
There are many advantages to mandating CSR policies and practices that deal with the use of energy, with much that that responsibility of promoting green-based approaches and sustainability as part of a socially responsible company on it marketing activities. It is important to identify what each organization could do to promote environmental gains directly related to the use of energy and the need to minimize the use of green-washing campaigns in order to boost company's reputation at minimal costs. Market expectations general illustrate that if an organization does not provide certain services or products in a satisfactory manner, another organization will gain business or popularity. Public awareness of energy, CSR, and eco-friendly actions at the corporate level are increasing playing a role in the global economy and empowered customers' purchase intentions.
\end{abstract}

As the demand for certain services and industries have increased, so has the use of use of new technologies and strategies. Organizations often welcome changes in procedures as it increases productivity and also increases their competitive advantage. Organizations within varying industries have become aware of the additional resources required to support increased demand and increased use of innovative technologies. They have also become aware of the many negative effects on the physical environment and cots with displaced human capital. Management in these organizations hopefully understand that resources must be protected and preserved for the future. Within the U.S., corporate social responsibility (CSR) is not itself well-regulated, but is increasingly become more of a strategic issue (Detomasi, 2008; Fernando, Saad, \& Haron, 2012; Franklin, 2008; Freeman, 1984; Galbreath, 2009). This lack of regulation and enforcement causes the responsibility of adhering to beneficial practices to have become a voluntary action within organizations. CSR, in relation to specific industries, can relate to general willingness and ability to directly and/or indirectly help its community in which it does the majority of its business. CSR deals directly with a form of self-regulation as there are is not formal established regulation within the U.S. currently. In many cases, social responsibility programs are officially instituted by organizations by incorporating efforts into their specific business models. Kotler and Lee (2005) suggested that "corporate social responsibility is a commitment to improve community well-being through discretionary business practices and contributions of corporate resources" (p. 3). This 
suggests that actions related to CSR are usually voluntary and are discretionary in nature.

Industries, such as those who use a large amount of energy, should be at the forefront of implementing CSR principles within their particular organizations. It is vital that the United States quickly recognizes the need for mandated CSR laws to ensure the protection and use of resources. Both environmental responsibilities and social ones should be clearly defined and mandated. There are "increased pressures to prove the business and social value of allocations of scarce resources", like energy (Kotler \& Lee, 2005, p 2). Corporate social initiatives are no longer enough to ensure pertinent practices are followed and effective strategies are employed to mandate the use of energy. The World Business Council for Sustainable Development (WBCSD) reported that current CSR refers to "business commitment to contribute to sustainable economic development, working with employees, their families, the local community, and society at large to improve their quality of life" (Kotler \& Lee, 2005, p. 3). The need to become more sustainable is increasingly important as many specific dwindling resources including energy become apparent.

There are a plethora of advantages to the implementation of mandated CSR practices to legislate energy within the U.S. These advantages include increased industry stimulation by increased sustainable development, increased market expectations, increased accountability as well as prolonged protection of the dwindling resource, especially as it refers to energy. Research traditionally shows that organizations who disregard their responsibility to execute their social responsibility towards their customers, employees, the environment and society as a whole will not be able to remain successful in the long run (Büchner, 2010). Schjeldahl (2013) suggested that "anything less than a well-organized approach to sustainability is likely to eat up resources and fall short of the desired results" (p. 11). This is important to remember as preservation of resources like energy is essential for the survival of the world. If CSR-embedded practices to promote the protection of energy use were enacted, many organizations would increase their financial success over time. This increased success would stimulate the industry and promote prolonged competitive advantages for those who abide by legislation.

Increased market expectations would also stimulate the industry and provide a continuance of hope for future endeavors that rely on the use of energy for success. Noteworthy research has provided that "the driving force behind the rising significance of CSR is capital market expectations" (Büchner, 2010, p. 41-42). The strong push for the importance of implementing CSR within all organizations is being propelled by the increasing market expectations. In order to be successful over time, many factors must culminate within an organization. It is imperative that organizations make sure their employees are treated right, ethical business practices are followed, and revenue is earned honestly. It is generally assumed that market expectations tie in to all of these specific factors (Ayres \& Ayres, 2013; Bone, 2014; 
Branco \& Delgado, 2012). Market expectations show that if an organization does not provide certain services or products in a satisfactory manner, another organization will gain business or popularity (Smith, 2010, 2012). Organizations should "devise expectations concerning their impacts on the environment, release information with transparency, and set achievable environmental goals" (Bone, $(2014$, p. 88). If employees are treated correctly all the time, business practices are followed ethically down to the very last detail, and consumers are respected an organization can withstand the competition or economic challenges much easier. Increased market expectations would be promoted if the CSR practices relating to the precious resource, energy, could be legislated.

Accountability is of great importance within all industries. Organizations that use large amounts of energy should operate under mandated standards that ensure the use of energy is necessary. Although many decisions may be made by a organization, there should still be governing bodies that ensure standards are met and resources are conserved for future generations to have access to. Having an increased amount of accountability is a very positive function within various industries today that use large amounts of energy. Legislation of CSR procedures related to energy consumption or use would keep business practices and ethical concerns constantly mandated and publicly reviewed. Some research have demonstrated that "there is current pressure on the SEC to require companies to assess and disclose on not only climate-related risks but also other material environmental, social, and governance risks" (Sarfat, 2013, p. 602). With the advent of legislation, specific practices to protect the use of energy and document related factors could be put in place to ensure accountability across the nation. Increased accountability also provides added protections to many organizations. Accountability provides protections to the material work, social systems and governance practices employed within organizations. Increased accountability and legislating governing bodies should increase safety and implementation of proper business practices in every industry that uses energy.

As it is relative clear there are many advantages to mandating CSR policies and practices that deal with the use of energy, it is important to identify specifically what each organization could do to promote environmental gains directly related to the use of energy. Organizations can all utilize "technology such as Skype and email to obviate the need for travel to meetings and to reduce paper consumption, while engaging in environmentally friendly practices ranging from the use of electric cars to the recycling of rubbish" (Tian \& Martin, 2012, p. 107). These strategies encourage short term and long term environmental goals.

It has been established that there is no current specific legislation over CSR. Reporting and voluntary programs are all that exist to currently promote CSR in relation to energy. In the last decade, the popularity of reporting on CSR has risen. Branco and Delgado (2012) reported that there have been "international attempts to 
improve the transparency by reporting" (p. 357). The United Nations Global Compact (UNGC), the Organisation for Economic Co-operation, the Development (OECD), and the Guidelines for Multinational Enterprises and the Global Reporting Initiative's (GRI) Sustainability Reporting Guidelines are all organizations that deal with CSR reporting. Such that programs as the UNGC, the OECD Guidelines, and the GRI guidelines are all imperative in the role of offering "the trust-based informal social norms, without which markets and societies cannot function" (p. 357). CSR deals with certain issues that relate to relations with consumers and the local community, health and safety within the work place, and the protection of the environment. Reporting can be defined more specifically as "a concept whereby companies decide voluntarily to contribute to a better society and a cleaner environment" (p. 357). Currently, CSR reporting deals with the voluntary disclosure of information that relates to economic, environmental and social aspects that can be influenced by certain organization's activities (Branco \& Delgado, 2012, p. 357). Branco and Delgado further suggested that sustainability reporting may be defined as the "preparation and publication of an account about an organization's social, environmental, employee, community, customer and other stakeholder interactions and activities" (p. 358). Positive and negative impacts may include increase in community involvement, increase or decrease in environmental issues, increase or decrease in awareness of ethical issues, and increased focus on employee-related concerns. Although reporting can bring about some positive change, there are many challenges associated with this function. These challenges include:

1. Outcomes cannot be measured directly for activities which are preventive, and when corruption occurs, it may remain undetected.

2. Countering corruption is complex, and related issues are often technical.

3. There are many forms of corruption.

4. Companies can find it difficult to discuss countering corruption publicly for fear that raising the topic may generate suspicions of problems.

5. Differences exist in reporting practices across cultures and business sectors (p. 361).

Reporting and the implementation of other mandates are essential to sustain the environmental resources, like energy, for upcoming generations, if significant progress is to be made in countering negative aspects of CSR and sustainability strategic initiatives. For example, newly established legislation could "support a preventative approach to environmental challenges, develop initiatives that promote greater environmental responsibility, and encourage the development and the diffusion of technologies that do not harm the environment" (Nunes, Valle, \& Peixoto, 2010 , p. 322). Ultimately, legislation should promote a healthy future for the industries that rely heavily upon the use of energy.

KEY WORDS: carbon footprint, CSR, eco-friendly, green marketing, OECD Guidelines. 
Relevance to Marketing Practitioners: This case study is relevant to marketers and researchers in dealing with ethical dilemmas and environmental sustainability issues for management in formulating their CSR policies and practices.

TRACK: Green Marketing/Sustainability 